\title{
Editorial
}

\section{Controlled Attenuation Parameter as a Noninvasive Method to Detect and Quantify Hepatic Steatosis in Chronic Liver Disease: What Is the Clinical Relevance?}

\author{
Mariana Verdelho Machado \\ Serviço de Gastrenterologia e Hepatologia, Hospital de Santa Maria, CHLN, Lisbon, Portugal
}

Keywords

Steatosis - Controlled attenuation parameter - Chronic hepatic disease

\section{Controlled Attenuation Parameter, um Método Não-Invasivo para Detectar e Quantificar a Esteatose Hepática na Doença Hepática Crónica: Qual É a Relevância Clínica?}

\section{Palavras Chave}

Esteatose · Controlled attenuation parameter - Doença hepática crónica

Ectopic accumulation of lipids in the liver, also known as hepatic steatosis, is a common finding [1]. It occurs in $90 \%$ of the heavy drinkers [2] and $20-30 \%$ of the nondrinkers [3], dubbed alcoholic and nonalcoholic fatty liver disease, respectively. Because of its growing prevalence in the general population, there is also a growing association of hepatic steatosis and other forms of chronic liver disease such as viral, autoimmune, and metabolic liver diseases [4].

\section{KARGER}

E-Mail karger@karger.com www.karger.com/pjg (c) 2017 Sociedade Portuguesa de Gastrenterologia Published by S. Karger AG, Basel

Karger

Open access

This article is licensed under the Creative Commons AttributionNonCommercial-NoDerivatives 4.0 International License (CC BYNC-ND) (http://www.karger.com/Services/OpenAccessLicense). Usage and distribution for commercial purposes as well as any distribution of modified material requires written permission.
The gold standard for the diagnosis and quantification of hepatic steatosis has been liver biopsy. However, liver biopsy has accuracy issues due to the nonhomogeneous distribution of liver steatosis throughout the liver that imposes important sample errors. In addition, it is an invasive procedure, with an unneglectable risk of complications [5]. As such, the search for noninvasive methods to diagnose and quantify liver steatosis has been a matter of intense research in the last decade. Magnetic resonancederived techniques such as spectroscopy and measurement of proton density fat fraction are highly reliable methods, probably superior to liver histology, particularly proton density fat fraction, which allows quantification of hepatic steatosis throughout the liver [6]. However, those methods are expensive, time-consuming, and not widely available. Ultrasonography and tomography scan has similar accuracy, although the latter is more expensive and imposes exposure to radiation [7]. They have excellent accuracy for moderate-to-severe steatosis (85\% sensitivity and $94 \%$ specificity). However, sensitivity decreases dramatically for steatosis $<30 \%$ [8]. Ultrasonography allows subjective semiquantification of steatosis. Since recently, the elastography Fibroscan ${ }^{\circledR}$ probe can incorporate the measurement of the degree of ultrasound attenuation by hepatic fat, controlled attenuation parameter (CAP) allowing indirect quantification of liver ste-

Dr. Mariana Verdelho Machado

Serviço de Gastrenterologia, Hospital de Santa Maria

Av. Prof. Egas Moniz

PT-1649-035 Lisbon (Portugal)

E-Mail mverdelhomachado@gmail.com 
atosis [6]. CAP results are expressed in decibels per meter $(\mathrm{dB} / \mathrm{m})$ and range from $100-400 \mathrm{~dB} / \mathrm{m}$. CAP has been consistently shown, in more than 20 small studies, to be able to separate different grades of steatosis, albeit with some degree of overlap between different grades [6]. Furthermore, cutoffs vary between studies, though values higher than $250 \mathrm{~dB} / \mathrm{m}$ consistently associate with at least moderate steatosis. Studies comparing the accuracy of CAP and ultrasonography for the diagnosis of liver steatosis are discordant, with some suggesting CAP to be superior, whereas others finding similar accuracy $[9,10]$. CAP is, however, less accurate than magnetic resonancederived techniques [11].

CAP has some limitations. It is only available in the Fibroscan $\mathrm{M}$ probe, though a CAP algorithm for the Fibroscan XL probe is being developed [12]. Failure to obtain a CAP measurement occurs in $6-8 \%$ and associates with older age, a higher body mass index, presence of the metabolic syndrome, and female gender [13].

In this issue of Portuguese Journal of Gastroenterology, Andrade et al. [14] presented a prospective study in 159 patients with chronic liver disease from different etiologies and compared liver steatosis determined by CAP and liver histology. The authors included patients with nonalcoholic fatty liver disease (NAFLD) and chronic viral hepatitis. They described a high accuracy for detecting mild steatosis (S1, 5-33\%), moderate (S2, 34-66\%), and severe steatosis (S3, >66\%) with AUROC 0.822, 0.956, and 0.976, respectively, which is better than previously described in the literature [15]. As expected, in this study, significant steatosis (which was considered when at least S2), associated with metabolic factors such as arterial hypertension, dyslipidemia, type 2 diabetes mellitus, and body mass index. It did not associate with the degree of fibrosis or necroinflammatory activity. However, more important than this analysis would be to determine which factors could have an impact on the accuracy of CAP to detect/quantify hepatic steatosis. For example, it has been described in the literature that, unlike hepatic elastography, CAP is not affected by the cause of chronic liver disease [16]. However, CAP accuracy is affected by obesity and larger skin-tocapsule distance, which may cause overestimation of steatosis. In fact, a skin-to-capsule distance higher than 25 $\mathrm{mm}$ is associated with a $60-70 \mathrm{~dB} / \mathrm{m}$ increase in CAP measurements [17]. Similarly, for lower grades of hepatic steatosis, the presence of significant fibrosis (defined as liver elastography higher than $10.1 \mathrm{kPa}$ ) may overestimate steatosis, with a higher CAP determination [18]. The reverse is also true, that is, liver elastography increases according to CAP. Some authors even advocate that, in patients with
NAFLD, CAP should always be considered in order to avoid overestimation of liver fibrosis [18].

The next question that needs to be answered is to what extend the diagnosis of liver steatosis influences the management of patients with chronic liver disease. Regarding chronic hepatitis $\mathrm{B}(\mathrm{CHB})$, evidence does not support a role of hepatic steatosis on the progression of chronic liver disease, prognosis, or response to antiviral treatment [19-21]. In CHB, hepatic steatosis did not associate with increased levels of aminotransferases and negatively associated with $\mathrm{HB}$ viral load [22]. It also associated with an increased rate of $\mathrm{HB}$ antigen loss in 1 study [23]. On the contrary, the presence of nonalcoholic steatohepatitis can be a cause of increased aminotransferases in an inactive $\mathrm{HB}$ antigen carrier, which may lead to unnecessary antiviral treatment [24]. Probably, patients with $\mathrm{CHB}$, liver steatosis, and persistent increase in aminotransferases should perform a liver biopsy to distinguish between viral-induced versus nonalcoholic steatohepatitis-induced aminotransferase elevation and better select for antiviral treatment.

Regarding chronic hepatitis $\mathrm{C}(\mathrm{CHC})$, the impact of liver steatosis on the prognosis and response to interferon treatment is complex and depends on the nature of hepatic steatosis, whether it is genotype 3 viral related or metabolism related [25]. With the advent of direct antiviral therapies, which are highly effective and have virtually universal indication in patients with $\mathrm{CHC}$, liver steatosis is now a matter of lesser importance in $\mathrm{CHC}$.

Lastly, it is important to determine the real relevance of the degree of liver steatosis in the prognosis/management of patients with NAFLD. Is there any interest in quantifying liver steatosis? The amount of liver steatosis does not seem to correlate with liver prognosis [26, 27], and there is no evidence of long-term benefits for the progression of liver disease in strategies that achieve improvement of liver steatosis [28]. However, there is accumulated circumstantial evidence that not only the presence of liver steatosis, but also the severity of steatosis correlates with adverse cardiovascular outcomes. Several epidemiological studies and meta-analyses showed that NAFLD associated with different markers of subclinical atherosclerosis (increase in carotid intima media thickness, impaired flow-mediated vasodilation, increased arterial stiffness or coronary artery calcification) [29], as well as with more than $50 \%$ increased risk for fatal and nonfatal cardiovascular events [30]. The increase in cardiovascular events was $250 \%$ in patients with severe steatosis [30, 31]. Furthermore, subclinical markers of atherosclerosis present a dose-response increase in preva- 
lence according to steatosis grading by ultrasonography [32-37]. Finally, a small study reported a dose-dependent decrease in carotid intima media thickness, according to the decrease in the amount of steatosis, after a therapeutic intervention in patients with NAFLD [38]. That decrease was independent of weight loss.

In conclusion, CAP seems to be a reliable, easy method to detect and quantify liver steatosis. It should always be taken into consideration when performing hepatic elastography, since high CAP values may influence the measurement of elastography. It is not yet understood what the clinical relevance of detecting hepatic steatosis in non-NAFLD chronic liver diseases is. Regarding steatosis quantification, it does not seem to have an impact on liv- er prognosis, but it may influence cardiovascular prognosis, and long-term, noninvasive monitoring of hepatic steatosis quantification may have a clinical impact in the near future.

\section{Statement of Ethics}

This study did not require informed consent or review/approval by the appropriate ethics committee.

\section{Disclosure Statement}

The authors have no conflicts of interest to declare.

\section{References}

1 Sayiner M, Koenig A, Henry L, Younossi ZM Epidemiology of nonalcoholic fatty liver disease and nonalcoholic steatohepatitis in the United States and the rest of the world. Clin Liver Dis 2016;20:205-214

-2 McCullough AJ, O'Shea RS, Dasarathy S: Diagnosis and management of alcoholic liver disease. J Dig Dis 2011;12:257-262.

-3 Younossi Z, Henry L: Contribution of alcoholic and nonalcoholic fatty liver disease to the burden of liver-related morbidity and mortality. Gastroenterology 2016;150:17781785.

4 Cortez-Pinto H, Machado MV: Is NAFLD a cofactor in other liver diseases? Nutr Ther Metab 2010;28:151-160

5 Bravo AA, Sheth SG, Chopra S: Liver biopsy. N Engl J Med 2001;344:495-500.

-6 Stern C, Castera L: Non-invasive diagnosis of hepatic steatosis. Hepatol Int 2017;11:70-78.

7 Machado MV, Cortez-Pinto H: Non-invasive diagnosis of non-alcoholic fatty liver disease. A critical appraisal. J Hepatol 2013;58:10071019.

8 Hernaez R, Lazo M, Bonekamp S, Kamel I, Brancati FL, Guallar E, Clark JM: Diagnostic accuracy and reliability of ultrasonography for the detection of fatty liver: a meta-analysis. Hepatology 2011;54:1082-1090.

-9 Yilmaz Y, Ergelen R, Akin H, Imeryuz N: Noninvasive detection of hepatic steatosis in patients without ultrasonographic evidence of fatty liver using the controlled attenuation parameter evaluated with transient elastography. Eur J Gastroenterol Hepatol 2013;25: 1330-1334.

10 Carvalhana S, Leitao J, Alves AC, Bourbon M, Cortez-Pinto H: How good is controlled attenuation parameter and fatty liver index for assessing liver steatosis in general population: correlation with ultrasound. Liver Int 2014; 34:e111-e117.
11 Hines CD, Frydrychowicz A, Hamilton G, Tudorascu DL, Vigen KK, Yu H, McKenzie CA, et al: $\mathrm{T}(1)$ independent, $\mathrm{T}(2)\left(^{*}\right)$ corrected chemical shift based fat-water separation with multi-peak fat spectral modeling is an accurate and precise measure of hepatic steatosis. J Magn Reson Imaging 2011;33:873881.

12 Sasso M, Audiere S, Kemgang A, Gaouar F, Corpechot C, Chazouilleres O, et al: Liver steatosis assessed by controlled attenuation parameter (CAP) measured with the XL probe of the FibroScan: a pilot study assessing diagnostic accuracy. Ultrasound Med Biol 2016; 42:92-103.

13 de Ledinghen V, Vergniol J, Capdepont M, Chermak F, Hiriart JB, Cassinotto C, et al: Controlled attenuation parameter (CAP) for the diagnosis of steatosis: a prospective study of 5,323 examinations. J Hepatol 2014;60: 1026-1031.

14 Andrade P, Rodrigues S, Rodrigues-Pinto E, Gaspar R, Lopes J, Lops S, Macedo G: Diagnostic accuracy of controlled attenuation parameter for detecting hepatic steatosis in patients with chronic liver disease. GE Port J Gastroenterol2017,DOI: 10.1159/000453364.

$D_{15}$ Shi KQ, Tang JZ, Zhu XL, Ying L, Li DW, Gao $\mathrm{J}$, et al: Controlled attenuation parameter for the detection of steatosis severity in chronic liver disease: a meta-analysis of diagnostic accuracy. J Gastroenterol Hepatol 2014;29: 1149-1158.

-16 Kumar M, Rastogi A, Singh T, Behari C, Gupta E, Garg H, et al: Controlled attenuation parameter for non-invasive assessment of hepatic steatosis: does etiology affect performance? J Gastroenterol Hepatol 2013;28: 1194-1201.
17 Shen F, Zheng RD, Shi JP, Mi YQ, Chen GF, $\mathrm{Hu} \mathrm{X}$, et al: Impact of skin capsular distance on the performance of controlled attenuation parameter in patients with chronic liver disease. Liver Int 2015;35:2392-2400.

18 Petta S, Wai-Sun Wong V, Camma C, Hiriart JB, Wong GL, Marra F, et al: Improved noninvasive prediction of liver fibrosis by liver stiffness measurement in patients with nonalcoholic fatty liver disease accounting for controlled attenuation parameter values. Hepatology 2017;65:1145-1155.

19 Jin X, Chen YP, Yang YD, Li YM, Zheng L, Xu CQ: Association between hepatic steatosis and entecavir treatment failure in Chinese patients with chronic hepatitis B. PLoS One 2012;7:e34198.

20 Ates F, Yalniz M, Alan S: Impact of liver steatosis on response to pegylated interferon therapy in patients with chronic hepatitis B. World J Gastroenterol 2011;17:4517-4522.

21 Cindoruk M, Karakan T, Unal S: Hepatic steatosis has no impact on the outcome of treatment in patients with chronic hepatitis B infection. J Clin Gastroenterol 2007;41:513-517.

22 Machado MV, Oliveira AG, Cortez-Pinto H: Hepatic steatosis in hepatitis B virus infected patients: meta-analysis of risk factors and comparison with hepatitis $\mathrm{C}$ infected patients. J Gastroenterol Hepatol 2011;26:1361-1367.

23 Chu CM, Lin DY, Liaw YF: Clinical and virological characteristics post HBsAg seroclearance in hepatitis B virus carriers with hepatic steatosis versus those without. Dig Dis Sci 2013;58:275-281.

24 Charatcharoenwitthaya P, Pongpaibul A, Kaosombatwattana U, Bhanthumkomol P, Bandidniyamanon W, Pausawasdi N, Tanwandee T: The prevalence of steatohepatitis in chronic hepatitis B patients and its impact on disease severity and treatment response. Liver Int 2017;37:542-551.
CAP: A Method to Detect and Quantify

Hepatic Steatosis in Chronic Liver Disease 
25 Machado MV, Cortez-Pinto H: Insulin resistance and steatosis in chronic hepatitis C. Ann Hepatol 2009;8(suppl 1):S67-S75.

26 Angulo P, Kleiner DE, Dam-Larsen S, Adams LA, Bjornsson ES, Charatcharoenwitthaya $\mathrm{P}$, et al: Liver fibrosis, but no other histologic features, is associated with long-term outcomes of patients with nonalcoholic fatty liver disease. Gastroenterology 2015;149:389397 e310.

-27 Ekstedt M, Hagstrom H, Nasr P, Fredrikson M, Stal P, Kechagias S, Hultcrantz R: Fibrosis stage is the strongest predictor for diseasespecific mortality in NAFLD after up to 33 years of follow-up. Hepatology 2015;61: 1547-1554.

28 Machado MV, Cortez-Pinto H: Non-alcoholic fatty liver disease: what the clinician needs to know. World J Gastroenterol 2014;20: 12956-12980.

29 Oni ET, Agatston AS, Blaha MJ, Fialkow J, Cury R, Sposito A, et al: A systematic review: burden and severity of subclinical cardiovascular disease among those with nonalcoholic fatty liver; should we care? Atherosclerosis 2013;230:258-267.
30 Targher G, Byrne CD, Lonardo A, Zoppini G, Barbui C: Non-alcoholic fatty liver disease and risk of incident cardiovascular disease: a meta-analysis. J Hepatol 2016;65:589-600.

31 Pisto P, Santaniemi M, Bloigu R, Ukkola O, Kesaniemi YA: Fatty liver predicts the risk for cardiovascular events in middle-aged population: a population-based cohort study. BMJ Open 2014;4:e004973.

32 Lee YH, Wu YJ, Liu CC, Hou CJ, Yeh HI, Tsai $\mathrm{CH}$, et al: The severity of fatty liver disease relating to metabolic abnormalities independently predicts coronary calcification. Radiol Res Pract 2011;2011:586785.

33 Li X, Xia M, Ma H, Hofman A, Hu Y, Yan H, et al: Liver fat content is associated with increased carotid atherosclerosis in a Chinese middle-aged and elderly population: the Shanghai Changfeng study. Atherosclerosis 2012;224:480-485.

34 Emre A, Terzi S, Celiker E, Sahin S, Yazici S, Erdem A, et al: Impact of nonalcoholic fatty liver disease on myocardial perfusion in nondiabetic patients undergoing primary percutaneous coronary intervention for ST-segment elevation myocardial infarction. Am J Cardiol 2015;116:1810-1814.
35 Lee JI, Kim MC, Moon BS, Song YS, Han EN, Lee HS, et al: The relationship between 10 year cardiovascular risk calculated using the pooled cohort equation and the severity of non-alcoholic fatty liver disease. Endocrinol Metab (Seoul) 2016;31:86-92.

36 Chiang CH, Huang CC, Chan WL, Chen JW, Leu HB: The severity of non-alcoholic fatty liver disease correlates with high sensitivity Creactive protein value and is independently associated with increased cardiovascular risk in healthy population. Clin Biochem 2010;43: 1399-1404.

-37 Sapmaz F, Uzman M, Basyigit S, Ozkan S, Yavuz $B$, Yeniova $A$, et al: Steatosis grade is the most important risk factor for development of endothelial dysfunction in NAFLD. Medicine (Baltimore) 2016;95:e3280.

- 38 Bhatia L, Scorletti E, Curzen N, Clough GF, Calder PC, Byrne CD: Improvement in nonalcoholic fatty liver disease severity is associated with a reduction in carotid intima-media thickness progression. Atherosclerosis 2016; 246:13-20. 